www.jmscr.igmpublication.org

Impact Factor (SJIF): 6.379

Index Copernicus Value: 71.58

ISSN (e)-2347-176x ISSN (p) 2455-0450

crossrefDOI: https://dx.doi.org/10.18535/jmscr/v6i6.178

Journal Of Medical Science And Clinical Research

IGM Publication

An Official Publication of IGM Publication

\title{
Morphometric Measurements of Human External Ear in student Population
}

\author{
Authors \\ Dr Sangeetha.S ${ }^{1}$, Dr Venkata Krishna.BR ${ }^{2}$ \\ ${ }^{1}$ Dept of Anatomy, TOMCH \& RC, Bangalore \\ ${ }^{2}$ Dept of Surgery TOMCH \& RC, Bangalore \\ Corresponding Author \\ Dr Venkata Krishna.BR
}

Dept of Surgery, TOMCH \& RC, Yadavanahalli, Attibele Hobli Anekal Taluk, Bangalore -562106

Ph no-9632470171, Email: sangeethavenkat33@gmail.com

\begin{abstract}
Introduction: In the adult the ear forms one anatomic unit serving both hearing and equilibrium. The external ear consists of pinna and external auditory canal concerned with hearing. Morphometric study of the external ear is of importance to physical anthropologists, physicians, forensic scientists and plastic surgeons.

This study aimed to determine the mean values of different morphometric measurements from the left and right ears in the study population.

Aim: To study the morphometric variations of pinna among students

Methods: Measurements were taken from 384 healthy medical students aged 17 - 20 years using a standard vernier callipers. The parameters measured were total ear height (TEH), ear width (EW).

Results: In our study we found that ear height and ear width values were more in right ears than left ears. All parameter values were more in males than females and their difference was statistically significant.

Discussion: Knowledge of normal ear dimensions is important in the diagnosis of congenital malformations and acquired deformities and in the planning of treatment. It is also helpful in hearing instrument industry and forensic criminology. We believe the data presented in this study have yielded parameters for ear morphology that will prove useful in determining ear anomalies and variations, and may help the clinician to reproduce an anatomically correct ear during its reconstruction.
\end{abstract}

Keywords: Morphometry; pinna; vernier callipers.

\section{Introduction}

The ear is an important component of facial complex, which gives an impression of its bearer`s age and sex. Its size, shape, and spatial location on the face are important from an aesthetic point of view. Any abnormality is an indication of a possible anomaly in the subject. ${ }^{[1]}$ Anomalies of the ear such as lobule ptosis, missing external ear, prominent ears and microtia may result from trauma, surgical resection, tumours or congenital deformities. ${ }^{[2]}$ Surgical correction of anomalies are required for psychological stability of the subjects. Over the recent past various studies have been conducted on morphometry of the external ear from different parts of the world. All these studies have shown that there is a high degree of 
variability in most of the measurements. These studies prove that much variability exists depending on the age, sex, ethnic group and even in the same person between the right and left ears. $^{[3]}$ Auricular appearance and symmetry contribute enormously to the facial aesthesis. Any auricular defect in the form of disproportionate size, abnormal elongation of the auricular lobe, or a missing part is corrected by surgery. ${ }^{[4]}$ For rectifying such abnormalities, a plastic surgeon requires information about normal auricular dimensions, the auricle's bilateral position on the face, and general conformation.

There are many studies on ear morphometry in literature. The shape, size and orientation of each pinna is as individual as a fingerprint, but it is possible to make some generalisations; men have larger ears than women, ears increase in both length and width with increasing age, and overall ear size differs according to ethnic group. ${ }^{[5]}$

Knowledge of normal ear dimensions may be useful as a guideline for the plastic surgeon rectifying possible defects, for the forensic specialist in identifying a person and also for the manufacturer in making ear prosthesis.

In this study attempt has been made to measure the differences in dimensions of external ear among student population. This study is required for better designing of ear phones, hearing aids and mufflers and also for plastic surgeons to plan reconstructive surgeries.

\section{Material and Methods}

The study was carried out on 384 students of age group $17-20$ years with no evidence of congenital ear anomalies or previous ear surgeries. The purpose of the study was explained to them and informed consent was taken. Clearance of institutional ethical committee was obtained before starting the work.

Standardized measurements of the ear lobule were taken according to landmark points defined by De Carlort al. The parameters measured were Total Ear Height (TEH) and Ear Width (EW). The TEH was taken as the distance from the most superior position of the helix to the most inferior projection of ear lobule. The EW was taken as the distance between the most anterior and posterior points of the ear.

All the measurements were taken by a single investigator using standard vernier callipers capable of measuring to the nearest $0.1 \mathrm{~mm}$. For each volunteer the measurements were carried out twice to ascertain accuracy.

The numerical data were analyzed using EPIINFO package version 3. 5. 3

Fig 1- The measurement of ear height by a vernier callipers

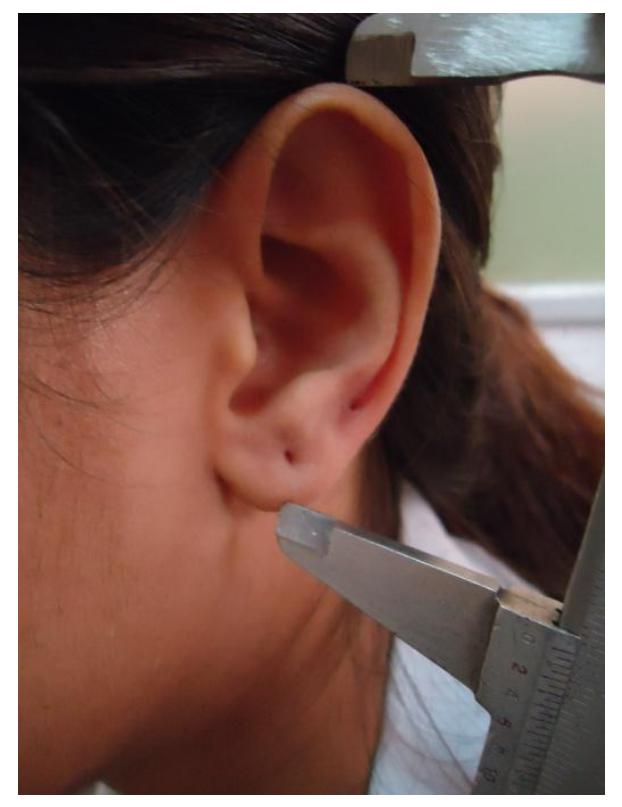

Fig 2- The measurement of ear width by a vernier callipers

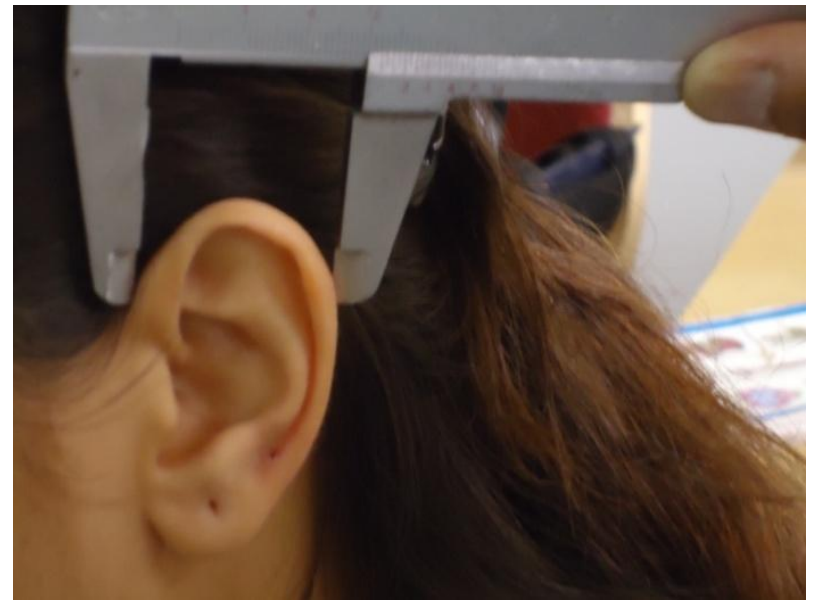




\section{Results}

Table 1 The mean morphometric measurements of the pinna $(n=384)$

\begin{tabular}{|l|c|c|c|}
\hline Parameters & Side & Mean +SD (in centimetres) & p value \\
\hline \multirow{3}{*}{ THE } & Right & $5.81 \pm 0.37$ & \multirow{3}{*}{0.69} \\
\cline { 2 - 3 } & Left & $5.80 \pm 0.36$ & \multirow{3}{*}{0.31} \\
\hline \multirow{3}{*}{ EW } & Right & $2.98 \pm 0.30$ & \\
\cline { 2 - 3 } & Left & $2.96 \pm 0.26$ & \\
\hline
\end{tabular}

Table 2 Comparison of ear measurements according to gender and side $n=384$

\begin{tabular}{|l|c|c|c|c|}
\hline Side & Parameter & Males & Females & p value \\
\hline \multirow{2}{*}{ RIGHT } & TEH & $5.99 \pm 0.31$ & $5.68 \pm 0.36$ & 0 \\
\cline { 2 - 5 } & EW & $3.13 \pm 0.27$ & $2.88 \pm 0.28$ & 0 \\
\hline \multirow{2}{*}{ LEFT } & THE & $5.99 \pm 0.32$ & $5.67 \pm 0.33$ & 0 \\
\cline { 2 - 5 } & EW & $3.10 \pm 0.25$ & $2.87 \pm 0.23$ & 0 \\
\hline
\end{tabular}

Table 3 Summary of various morphometry studies. Numbers represent distances in centimetres

\begin{tabular}{|l|c|c|c|c|c|}
\hline Study & Population & \multicolumn{2}{c|}{ Ear length } & \multicolumn{2}{c|}{ Ear width } \\
\hline & & Males & Females & Males & Females \\
\hline Deopa & Indian subcontinent & 6.04 & 5.76 & 3.04 & 2.88 \\
\hline Alexander & Indian subcontinent & 6.89 & 6.09 & 3.60 & 3.12 \\
\hline & Caucasian & 6.52 & 6.04 & 3.44 & 3.13 \\
\hline & Afro-caribbean & 6.27 & 6.04 & 3.38 & 3.23 \\
\hline Farkas & American Caucasian & 6.24 & 5.85 & 3.54 & 3.35 \\
\hline Bozkir & Turkish Caucasian & 6.31 & 5.97 & 3.33 & 3.13 \\
\hline Ferrario & Italian Caucasian & 6.31 & 5.73 & 3.81 & 3.50 \\
\hline Tayyar m & Turkish-caucasian & 6.45 & 6.03 & & \\
\hline Olasunkanmi & Nigerian & 5.5 & 5.5 & 3.4 & 3.4 \\
\hline Present study & Indian subcontinent & 5.99 & 5.67 & 3.12 & 2.87 \\
\hline
\end{tabular}

The measurements and comparison of results for the right and left ears are shown In Table 1. All parameter values are more in right ears than left ears.

According to Table 2 all parameter values are more in males than females and their difference is statistically significant.

\section{Discussion}

The human external ear is the defining feature of the face. Its structures are signs of age and sex. The appearance and symmetry of auricle is essential for facial harmony. Differences between the right and left parts of the human face, especially difference between paired structures , are well known in healthy people. ${ }^{[6]}$ Knowledge concerning the anatomy of the normal ear is important in the diagnosis of congenital malformations, syndromes, acquired deformities, as well as in planning of treatment. ${ }^{[7]} \mathrm{A}$ deformation in auricular shape and size or spatial dislocation of the auricle on the face can point towards a possible anomaly in the patient.

In the present study attempt was made to document the values of different morphometric measurements from the left and right pinna of the study population.

The total ear height is important in evaluation of congenital anomalies. The ear reaches its mature height at 13 years in males and 12 years in females. $^{[8,9]}$ Moreover the ancient Chinese believed that each part of the ear represented a different prospect, maintaining that the TEH shows association with long life and status. For eg: the kings of old china are said to have long ears. ${ }^{[10]}$

A study done by M G Bozkir et al on Turkese Caucasian population showed that the height of male ears was $6.3 \mathrm{~cm}$ and the female ear height was $5.96 \mathrm{~cm}^{\left[{ }^{[7]}\right.}$ Another study on Turkese Caucasian population done by M T Kalcioglu et al stated that the male ear height was $6.45 \mathrm{~cm}$ and female ear height was $6.03 \mathrm{~cm} \cdot{ }^{[11]}$ Alexander $\mathrm{K}$ 
analysed the study population of 420 volunteers into three ethnic groups and stated that the mean ear heights of Indian subcontinent population was $6.89 \mathrm{~cm}$ in males and $6.09 \mathrm{~cm}$ in females whereas the parameters in Caucasian group was $6.52 \mathrm{~cm}$ in males and $6.04 \mathrm{~cm}$ in females, and in AfroCaribbean population was $6.27 \mathrm{~cm}$ and $6.04 \mathrm{~cm}$ respectively. ${ }^{[12]} \mathrm{D}$ Deopa in his study found the mean height of male ears was $6.03 \mathrm{~cm}$ and in females $5.75 \mathrm{~cm} .{ }^{[13]}$ In our study the mean TEH of males was $5.99 \mathrm{~cm}$ and in females was $5.67 \mathrm{~cm}$ and these measurements were significant statistically whereas there was no statistical significance between the right and left ear heights. The mature width of the ear is achieved in males at 7 years and in females at 6 years. ${ }^{[8]}$ A study done by Deopa showed that in males, right EW was $3.02 \mathrm{~cm}$ and left EW was $3.06 \mathrm{~cm}$ and in females the right EW was $2.88 \mathrm{~cm}$ and left EW $2.87 \mathrm{~cm}$. He stated that male ears were wider than female ears and this difference was significant statistically. Bozkir's study showed that, in males the right EW was $3.31 \mathrm{~cm}$ and left EW was 3.33 $\mathrm{cm}$ and in females the right EW was $3.12 \mathrm{~cm}$ and the left EW was $3.13 \mathrm{~cm}$ stating that the male ears were wider than females. In Alexander K`s study, the EW showed a significant trend for males (Indian > Caucasian > Afro - Caribbean) but not for females. In our study, in males the right $\mathrm{EW}$ is $3.13 \mathrm{~cm}$ and left EW is $3.10 \mathrm{~cm}$ and in females the right $\mathrm{EW}$ is $2.88 \mathrm{~cm}$ and the left $\mathrm{EW}$ is 2.87 $\mathrm{cm}$. The ear width in males is more than that of females and this difference is significant statistically. But the difference between right and left EW is not significant statistically. These data concur with the observations of Deopa, Alexander, Farkas, Bozkir and Ferrario.

This study demonstrates the mean values of different morphometric measurements from the left and right ears of both sexes. We believe that the data presented in this study have yielded parameters for ear morphology that will prove useful in determining ear anomalies and variations, and may help the clinician to reproduce an anatomically correct ear during reconstruction.

\section{Conclusion}

With the Knowledge about the normal ear dimensions is important in the diagnosis of congenital malformations, and acquired deformities, as well as in the planning of treatment. This study provides the mean values of different morphometric measurements of left and right ear in the student population of Indian subcontinent. There is still need for future studies comparing populations with different social and ethnic background to interpret common knowledge about the size of the ear.

\section{References}

1. Ruma P, Singh P. Anthropometry of the normal human auricle: A study of adult Indian men. Journal of aesth plast surg 2007; 31: $372-379$

2. Coward T J, Watson R M, Scott B J. Laser scanning for the identification of repeatable landmarks of the ears and face. Br J Plastic Surg 1997; 50: 308 - 314.

3. Marras W S, Kim J K. anthropometry of Industrial populations, Ergonomics, 1993; 36: $371-78$.

4. Guyuron B, DeLuca L: ear projection and the posterior auricular muscle insertion. Plast Reconstr Surg 100: 457 - 460, 1997

5. Healthcote $\mathrm{J}$ A. Why do old men have big ears? BMJ 1995; 311: 1668.

6. Ferrario V F , Sforza C, Ciusa V, Dellavia C, Tartglia GM: the effect of sex and age of facial asymmetry in healthy subjects: A cross sectional study from adolescence to midadulthood. J Oral Maxillofac Surg 59:382 - 388, 2001

7. M G Bozkir, P Karakas and M Yavuz et al., Morphometry of the external ear in our adult population, Aesthetic Plast Surg 30,2006: $81-85$.

8. Farkas LG, Posnick JC, Hreczko TM: Anthropometric growth study of the ear. Cleft Palate Craniofac J 29:324 - 329, 1992 
9. Ito I, Imada M, Ikeda M, Sueno K, Arikuni T, Kida A:A morphological study of age changes in adult human auricular cartilage with speial emphasis on elastic fibres. Laryngoscope 111:881 -886, 2001

10. Woo PN, Lip PL:....and that thick ears signify greater wealth. BMJ 312:582, 1996

11. M T Kalcioglu, M C Miman and Y Toplu et al. anthropometric growth study of normal human auricle. Int $\mathbf{J}$ Pediatr Otorhynolaryngol 67, 2003: 1169 - 77

12. K S Alexander, D J Scott, B Sivakumar and $\mathrm{N}$ Kang. A morphometric study of the human ear. Journal of Plast, Reconstr and Aest Surg 64, 2011: $41-47$.

13. Deopa D, H K Thakkar, Chandra Prakash, R Niranjan, M P Barua. Anthropometric measurements of external ear of medical students in Uttarakhand region. Journal of anatomical society of India 2013; 62: 79 83. 